\title{
Diagnostic pure transgastric NOTES in an intensive therapy unit patient
}

\author{
Maciej Michalik, Maciej Bobowicz, Anna Trybull, Mieczysław Witzling \\ General and Vascular Surgery Department, Ceynowa Hospital, Wejherowo, Poland
}

Videosurgery and other miniinvasive techniques 2011; 6 (2): 108-110 DOI: $10.5114 /$ wiitm.2011.23220

\begin{abstract}
Natural orifice transluminal endoscopic surgery (NOTES) is a natural consequence of evolution in minimally invasive surgery. It allows one to reduce surgical trauma and the number of complications and to improve cosmetic outcomes. It also shortens the patient's recovery time. So far there have been only nine NOTES procedures performed in Poland and around 200 NOTES interventions performed worldwide. In this paper a transgastric diagnostic NOTES procedure in a critically ill patient is described. A 60-year-old male patient with multi-organ failure (circulatory, respiratory and renal insufficiency, with co-morbid hypothyroidism and diabetes mellitus) hospitalized in the intensive therapy unit (ITU) with unknown cause of his condition was qualified for transgastric diagnostic NOTES procedure. This intervention revealed the diagnosis of metastatic neoplastic disease and allowed persistent therapy to be avoided. Diagnostic NOTES in selected patients seems to be a very useful. It provides fast diagnosis with relatively small perioperative trauma. It is an easy procedure that requires a regular or operative endoscope, one surgeon and an endoscopic nurse. It can be done anywhere, including at the patient's bedside. It provides specimens for histopathology and speeds up diagnostics and decision making, especially in terminally ill patients.
\end{abstract}

Key words: natural orifice transluminal endoscopic surgery (NOTES), diagnostic NOTES, transgastric NOTES, pure NOTES, scar-free surgery, minimally invasive surgery.

\section{Introduction}

Currently, surgeons are trying to develop operative techniques that would allow surgery to become even less invasive than it is now. The initial phase of dynamic development of laparoscopic surgery that started in 1987 is beginning to evolve now. Nowadays, we are witnessing a new revolutionary idea, which is called natural orifice transluminal endoscopic surgery (NOTES) [1]. The use of a new approach to peritoneal access is very promising. Its development is not progressing as dynamically as laparoscopic surgery because many questions about the technique, medical and ethical aspects, as well as technological challenges arise [1, 2]. We still do not have a widely available flexible endoscope appropriate for application in NOTES surgery. Nevertheless, the idea of NOTES still persists, because NOTES permits scar-free surgery that is less invasive and almost painless postoperatively. The trauma is minimised, with better cosmetic results. It is also applicable as ambulatory surgery. Moreover, the majority of patients accept this method. Most of them would undergo the NOTES procedure if it was available [3].

In Poland there have been nine live human NOTES procedures performed so far. All of them were per- 
formed by one surgical team from the General and Vascular Surgery Department, Ceynowa Hospital, Wejherowo. Most of them used vaginal access [4]. The case described is the team's first experience with human transgastric NOTES surgery.

\section{Case report}

A 60-year-old male patient with multi-organ failure (circulatory, respiratory and renal insufficiency, with co-morbid hypothyroidism and diabetes mellitus) had been hospitalized in the intensive therapy unit (ITU) for four days. The diagnostic tests including abdominal ultrasound scan and computed tomography performed did not explain the causes of multiorgan insufficiency. Moreover, there were some discrepancies between the ultrasound scan (US) results and computed tomography (CT) examination. The US showed liver metastases, although the CT scan did not confirm that. The primary source of the potential metastases remained unknown. The patient required multiple interventions such as mechanical ventilation, circulatory support and haemodialysis. Despite the fact that all available diagnostic tests were performed, the diagnosis of the primary cause of the patient's state was still unknown. On these grounds, the decision to perform a diagnostic NOTES procedure through the transgastric access was made.

\section{Surgery description}

The surgery was performed at the ITU bedside by one surgeon and an endoscopic nurse, both experienced in endoscopy and animal and human NOTES procedures. The patient was placed in a supine position. A gastroscope (GIF-Q165, Olympus) was used in this intervention. Initially the oesophagus, stomach and duodenum were examined as in conventional gastroscopy. Then the anterior wall of the abdomen was pressed with a finger analogously to the way the percutaneous endoscopic gastrectomy (PEG) insertion point is established. A diathermic loop (COOK ASM-1-S) was used to cut the stomach wall open. Rigid endoscopic forceps (COOK RBF-2.4-160-S) were used as a sort of guide wire for the gastroscope to enable abdominal cavity entry. Exploration of the abdominal cavity was performed. Adhesions were identified in the right lower abdominal quadrant. Moreover, wide neoplastic dissemination in the abdominal cavity with distal metastases in both hepatic lobes was found. Multiple samples for histopathological exami- nation were taken. Next, the PEG was performed. Through the skin incision the guide wire was inserted. It was grasped with the endoscopic forceps, introduced into the stomach, and later taken outside via the oesophagus. Further steps followed the standard PEG insertion technique. When the PEG tube was in place it was pulled with the stomach wall against the peritoneum parietale. This way the stomach defect was closed. At this stage the whole transgastric diagnostic NOTES was finished. The operative time was $45 \mathrm{~min}$. Based on operative findings the decision against further unnecessary excessive treatment was made and palliative measures were introduced. The patient died on the first postoperative day due to multi-organ failure secondary to advanced metastatic cancer.

\section{Discussion}

Until 31 August 2009 many NOTES procedures on a porcine model or in humans were performed, for example: cholecystectomy, appendectomy, staging procedures, hemicolectomy, adhesiolysis, gynaecological or bariatric procedures [2, 4-9]. There have been 28 pure NOTES and 183 hybrid NOTES (laparoscopically assisted NOTES) procedures published so far. Reports describe small groups of 1 to 68 patients. So far, only 21 procedures have been performed through gastric access and others were performed through the vagina. In the US, 48 NOTES procedures have been performed: 16 of them through gastric access, 32 through vaginal access and only one of those was a pure NOTES [10].

It is hard to evaluate the NOTES method since there are only 200 cases of its application described. The "White Paper" of NOSCAR is neither generally accepted nor in common use [10]. The long duration of the NOTES procedure is due to the lack of experience. Consequently, surgeons prefer open or laparoscopic interventions. The literature outlines many complications of NOTES: peritonitis, bleeding of the gastric wall and oesophageal perforation to start with. Therefore we need reliable clinical trials that would show the advantages and possible risks of these procedures. The perception of NOTES is different between patients and surgeons. Among 192 patients, $56 \%$ chose cholecystectomy by NOTES rather than laparoscopic cholecystectomy. Only 93 (26\%) of 357 questioned surgeons chose NOTES cholecystectomy [3]. 
In the presented case the choice of abdominal cavity access was limited by the patient's gender. The transgastric access was deemed easier and safer for the patient than the transcolonic access, especially in view of the stomach decontamination issues [11]. Transecting the stomach and moving to the abdominal cavity was relatively easy. Compression of the anterior gastric wall through the abdominal wall allowed an appropriate choice of the transection point. Insufflation of the stomach during exterior compression pressed the stomach wall against the peritoneum and therefore prevented interposition of the transverse colon and small intestine. Adequate gas sealing was provided by the small incision and strict adjacency of the gastroscope and stomachs mucosa [12]. Inspection of the abdominal cavity was thorough and it was possible to achieve by moving the patient's bed to the sides as well as moving it up and down. Samples for histopathology were obtained with regular endoscopic instrumentation without difficulty. Stomach defect closure via PEG insertion was an easy step compared to alternative methods such as omentoplasty or placing "over-the-scope clips" $[13,14]$. In the case of the ITU team's decision to continue with the intensive treatment it could have been used as a feeding tube. Operative time was short. The procedure was performed at the bedside in the ITU by one surgeon and an endoscopic nurse; therefore logistically it was better and easier than laparoscopy or laparotomy, which would have required operating room access [1517]. The main disadvantage was the lack of possibility to inspect the extraperitoneal space.

There were several advantages of the NOTES in this particular patient. First of all, this intervention was relatively safe, simple and allowed the ITU bedside diagnosis without a major procedure or transporting the patient to the operating theatre. Secondly, the patient did not require any spasmolytics that could influence the pulmonary function [15].

\section{Conclusions}

Diagnostic NOTES in selected patients seems to be a very useful. It provides fast diagnosis with relatively small perioperative trauma. It is an easy procedure that requires a regular or operative endoscope, one surgeon and an endoscopic nurse. It can be done anywhere, including at the patient's bedside. It provides specimens for histopathology and speeds up diagnostics and decision making, especially in terminally ill patients.

\section{References}

1. Willingham FF, Brugge WR. Taking NOTES: translumenal flexible endoscopy and endoscopic surgery. Curr Opin Gastroenterol 2007; 23: 550-5.

2. Malik A, Mellinger JD, Hazey JW, et al. Endoluminal and transluminal surgery: current status and future possibilities. Surg Endosc 2006; 20: 1179-92.

3. Volckmann ET, Hungness ES, Soper NJ, Swanstrom LL. Surgeon perceptions of Natural Orifice Translumenal Endoscopic Surgery (NOTES). J Gastrointest Surg 2009; 13: 1401-10.

4. Michalik M, Orlowski M, Frask A, et al. NOTES cholecystectomy - the first experience in Poland. Videosurgery and other miniinvasive techniques 2009; 4: 42-5.

5. Auyang ED, Hungness ES, Vaziri K, et al. Human NOTES cholecystectomy: transgastric hybrid technique. J Gastrointest Surg 2009; 13: 1149-50.

6. Gumbs AA, Fowler D, Milone L, et al. Transvaginal natural orifice translumenal endoscopic surgery cholecystectomy: early evolution of the technique. Ann Surg 2009; 249: 908-12.

7. Nassif J, Zacharopoulou C, Wattiez A. Staging of gynaecological malignancies by natural orifice transluminal endoscopic surgery (N.O.T.E.S.). Surg Oncol 2009; 18: 147-52.

8. Cahill RA, Lindsey I, Cunningham C. Address of early stage primary colonic neoplasia by N.O.T.E.S. Surg Oncol 2009; 18: 163-8.

9. Asakuma M, Nomura E, Lee SW, Tanigawa N. Ancillary N.O.T.E.S. procedures for early stage gastric cancer. Surg Oncol 2009; 18: 157-61.

10. Soper N. ISDS Symposium: What's new in NOTES? Human experience - Latest on transgastric and transvaginal procedures. International Surgical Week ISW 2009, Adelaide, Australia, September 6-10, 2009.

11. Narula VK, Happel LC, Volt K, et al. Transgastric endoscopic peritoneoscopy does not require decontamination of the stomach in humans. Surg Endosc 2009; 23: 1331-6.

12. Nau P, Anderson J, Needleman B, et al. Endoscopic peritoneal access and insufflation: natural orifice transluminal endoscopic surgery. Gastrointest Endosc 2010; 71: 485-9.

13. Dray X, Giday SA, Buscaglia JM, et al. Omentoplasty for gastrotomy closure after natural orifice transluminal endoscopic surgery procedures. Gastrointest Endosc 2009; 70: 131-40.

14. Kratt T, Küper M, Traub F, et al. Feasibility study for secure closure of natural orifice transluminal endoscopic surgery gastrotomies by using over-the-scope clips. Gastrointest Endosc 2008; 68: 993-6.

15. Waydas C, Schneck G, Duswald KH. Deterioration of respiratory function after intra-hospital transport of critically ill surgical patients. Intensive Care Med 1995; 21: 784-978.

16. Onders RP, McGee MF, Marks J, et al. Natural orifice transluminal endoscopic surgery (NOTES) as a diagnostic tool in the intensive care unit. Surg Endosc 2007; 21: 681-3.

17. Witzling M, Michalik M, Pawlak M. NOTES in patients treated in intensive care units - the new challenge. Videosurgery and other miniinvasive techniques 2009; 4: 154-7. 